\title{
Os passos em volta de uma homenagem
}

\section{lsabel Pinto}

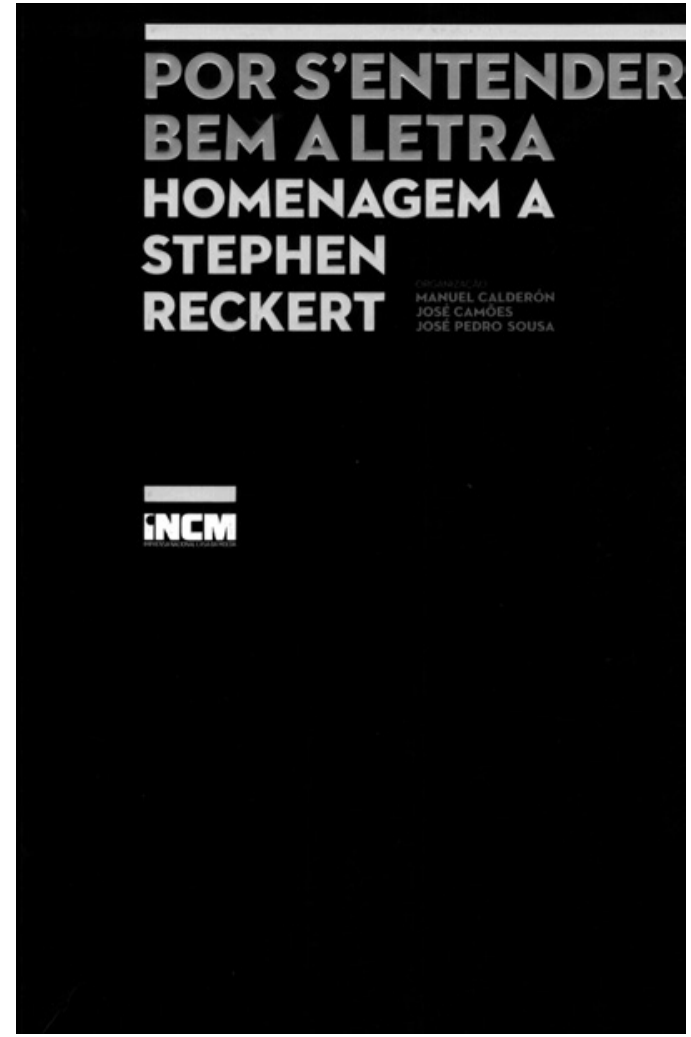

Manuel Calderón, José Camões e José Pedro Sousa (org.), Por s'entender bem a letra: Homenagem a Stephen Reckert, Lisboa, Imprensa Nacional - Casa da Moeda, 2011, $781 \mathrm{pp}$.

Treze anos depois de One Man's Canon: Five Essays on Medieval Poetry for Stephen Reckert (ed. Alan Deyermond, Department of Hispanic Studies, Queen Mary and Westfield College, 1998), vem a público novo volume de homenagem ao notável humanista, mais vasto na temática e nos intervenientes, desta vez da responsabilidade do Centro de Estudos de Teatro, com organização de Manuel Calderón, José Camões e José Pedro Sousa.

Foi pelo trilho comum do estudo da obra de Gil Vicente que o vínculo entre o Centro de Estudos de Teatro e Stephen Reckert, que, oportunamente, participou, em 2002, no Congresso Internacional Gil Vicente 500 anos depois, se estreitou. A sua obra Espirito e letra de Gil Vicente (1976, trad. port., 1983) forneceu linhas orientadoras para a reprodução fac-similada da Copilação de todalas Obras de Gil Vicente (vols. III e IV d' As obras de Gil Vicente), publicada no âmbito do Congresso, que muito beneficiou dos reparos de Stephen Reckert a edições anteriores, a propósito das exigências imputáveis ao fac-símile.

Cabe-nos, aqui, a grata função de deixar entrever as matérias, e respectiva dispositio, que o leitor poderá encontrar neste volume, de aspecto sóbrio, editado pela Imprensa Nacional-Casa da Moeda.

0 verso da Romagem dos agravados ("E pera declaraçãol desta obra santa et cetral quisera dizer quem sãol as figuras que virãol por s'entender bem a letra") que dá título ao livro é escolha certeira, porque logra conjugar a alusão à profundidade do labor de Stephen Reckert em prol do bom entendimento da "letra" (poesia medieval, teatro de Gil Vicente, poesia de Cesário Verde, etc.) com o fruto do seu percurso académico, bem patente no ecletismo linguistico e tópico deste volume de homenagem. As línguas são seis: português, castelhano, inglês, catalão, galego e italiano; os assuntos mais ainda, abarcando as sentidas evocações, as homenagens em exercício poético e as abordagens académicas de temas variados de pendor universal, que compreendem, entre outros, o teatro de Gil Vicente e a poesia popular, ou "lira mínima", como Stephen Reckert preferiu designá-la.

Pelo acima exposto acerca dos contributos que constituem o volume, facilmente se entende, e louva, a organização do volume em três secções: Evocatio, Inventio e Eruditio. Desta feliz opção, resulta uma coerência temática que convida e favorece a leitura.

Através dos textos integrados na primeira categoria o leitor fica com conhecimento de causa da vertente humana que, de modo consistente, configurou o percurso académico de Stephen Reckert; na segunda categoria, encontramos lira valiosa pela sua originalidade em contexto; os contributos compilados na última, e maior, secção confirmam o vigor do estudo crítico, decisivamente alentado pela clarividência do homenageado.

0 volume abre com uma resenha biográfica do homenageado, que se destaca pelo fulgor que a retrospectiva empresta aos factos benfazejos do passado. 0 escrutínio do percurso de Stephen Reckert encontra justo complemento na «Bibliografia de Stephen Reckert 1948-2011", tão completa quanto inspiradora.

Segue-se a Evocatio: Albert G. Hauf I Valls, C. Brian Morris, Helder Macedo e Marta de Senna descrevem a intersecção do seu próprio percurso com o de Stephen Reckert, acrescentando ao volume a dimensão inestimável da experiência pessoal.

Na Inventio, Alfonso Alegre Heitzmann, Casimiro de Brito, Ramon Dachs, Richard Zenith e Y. K. Centeno dedicam matéria escrita inédita da sua autoria ao homenageado, oferecendo ao leitor um registo poético de cumplicidade e reinvenção. lsabel Pinto,

Doutora em Estudos de Teatro, é investigadora do Centro de Estudos de Teatro da Faculdade de Letras da Universidade de Lisboa. 
A Eruditio é composta por cinquenta textos, ordenados alfabeticamente pelo nome dos autores; por clareza de exposição, proponho aqui a sua subdivisão também em três categorias: Gil Vicente, texto antigo (do século IV ao XVIII) e texto moderno.

Gil Vicente, objecto de estudo recorrente de Stephen Reckert, destaca-se, compreensivelmente, como figura de primeira ordem: Andrés José Pociña López explica de que modo uma leitura profícua de Auto dos físicos e Sermão de Abrantes envolve a consideração do ciclo folclórico do Carnaval e da Quaresma, pela existência nos dois textos de referentes alusivos aos mesmos; Isabel Almeida releva passos discursivos disfóricos em Triunfo do Inverno e do Verão, reportando a filiação no Auto dos Quatro Tempos, para problematizar a sua integração no encómio régio a D. João III; João Nuno Sales Machado indaga a letra vicentina por forma a encontrar as imagens, mais ou menos explícitas, da espectacularidade que as rege, através do paralelismo com as artes plásticas, apresentando, nomeadamente, o "restauro possivel" da cena final de Breve sumário da história de Deos; José Augusto Cardoso Bernardes revisita parte da obra vicentina sob o ponto de vista da autocensura, realçando a figura de Gil Terrón de Pastoril castelhano e do filósofo de Floresta de enganos, casos de "disfarce autoral", uma estratégia eficaz para desfeitear as imposições da Censura; Márcio Ricardo Coelho Muniz propõe os tratados políticos coevos como fonte vicentina, associada ao topos da "aderência do Paço", que denuncia uma política real rendida ao carácter arbitrário do favoritismo; Olinda Kleiman põe em causa uma linha ortodoxa de interpretação do teatro vicentino assente na vertente pedagógica, através de uma leitura farsesca e "zombeteira" do Auto da Índia; Sebastiana Fadda guia-nos numa digressão pelas traduções vicentinas mais recentes para francês, inglês, italiano e espanhol, avaliandoas; T. F. Earle detecta uma dimensão religiosa e mística em farsas como Quem tem farelos? e Auto da Índia, atribuindo ao burlesco sentidos implícitos a recensear Teresa Amado explora o paralelismo estrutural e semântico entre Auto de São Martinho e Pregação, mostrando como em ambos a vertente religiosa e moral desemboca numa crítica à corte em que foram representados; Ugo Serani questiona a condição de Gil Vicente como precursor imitador ou inventor, confrontando pontos de vista diversos, nomeadamente o do próprio Stephen Reckert, segundo o qual o artista exerce novas combinações de significantes conhecidos.

Em relação ao texto antigo, os artigos revêem, igualmente, matéria contígua aos interesses do homenageado: Anne M. Birrell dá-nos a conhecer as linhas temáticas da poesia breve da China, dos séculos IV e V ajustando um paralelismo entre estas e certo tipo de composições ibéricas; Armando López Castro decompõe a intencionalidade melancólica de Juan Ruiz, autor de Libro de buen amor, que pretende moralizar e entreter, sem, no entanto, escamotear as dúvidas e incertezas do

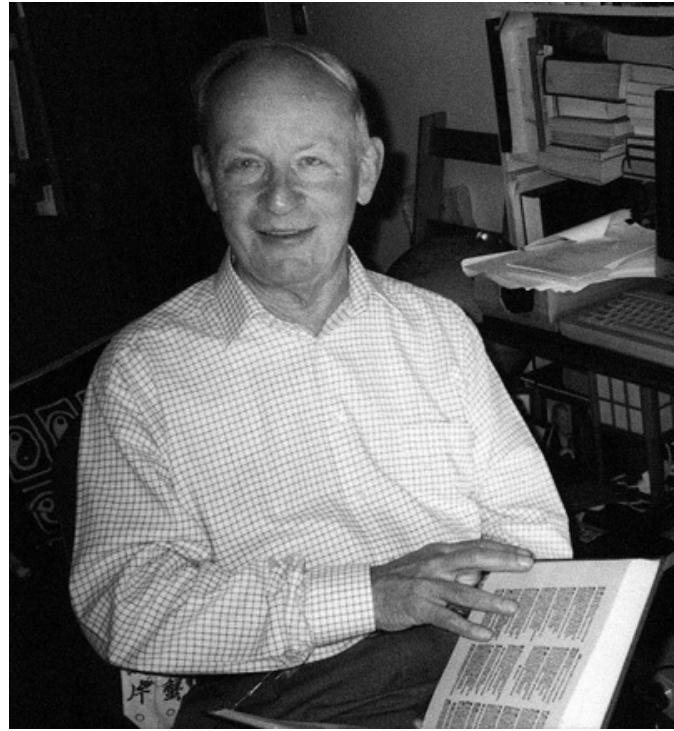

tempo presente; Artur Henrique Ribeiro Gonçalves inscreve 0 desgraciado amante, de Frei Gaspar Pires de Rebelo, e Tercera parte de Guzmán de Alfarache, do Marquês de Montebelo, na tradição da peregrinação pícara peninsular E. Michael Gerli apresenta uma leitura de Celestina, no âmbito da qual o móbil de todas as personagens é a veemência do desejo, ainda que conotado, no final, com desilusão, impotência e morte; Gema Vallín procura aprimorar a fixação de um poema português, Doportando nom mudar, incluído no Cancioneiro da Vaticana, dominado pelo tema da distância amorosa, tentando esclarecer os passos de sentido mais hermético; Helena Reis Silva estuda a figura do representador no corpus de teatro quinhentista, ponderando a sua versatilidade cénica e ficcional; Hélio J. S. Alves aplica o conceito de "microsignificantes" à análise da obra de Diogo Bernardes, recriando, assim, o texto "Micro-significantes na Semiótica de Camões", de Stephen Reckert; Isabel Pinto revisita o culto de Santa Maria Egipcíaca para, à luz do mesmo, filiar a Comédia intitulada Santa Maria Egipcíaca na extensa família de traduções portuguesas de comédias espanholas da segunda metade do século XVIII; István Rákóczi dá a conhecer matéria impressa de grande circulação, as chamadas folhas volantes, que, em Portugal, asseguravam a divulgação de factos e circunstâncias relativos à primeira etapa da guerra do turco na Hungria; José Javier Rodríguez Rodríguez sugere uma leitura dos sonetos XXVIII, En vano del incendio que te infama, e XXXII, Temes en vano al rayo que te ofende, de Francisco de Rioja, em que o autor concilia o discurso moralizante com a descontracção lúdica; José Manuel Pedrosa recupera a tradição lírica hispânica, através do tópico prolifero dos amores entre jovens desinibidas e médicos desenvoltos; Juliet Perkins revê o mito dos amores de Júpiter e Alcmena e o lugar central ocupado na intriga pela vingança de Juno, em duas comédias do século XVIII, uma de José de Cañizares e outra de António José da Silva; Luís de Oliveira e Silva compara gigantes, Adamastor e Briareu, para descobrir que enquanto o primeiro consegue suspender a acção de Vasco da Gama, o segundo integra o programa de acção de D. Quixote; Luiza Nóbrega questiona a supremacia atribuída pela crítica ao Consilio Olimpico em detrimento do Submarino, identificando-a com a resistência ao 
entendimento de Os lusíadas como poema híbrido, épico mas também trágico-lírico; Manuel Delgado Morales detém-se na melancolia religiosa de Crisanto, protagonista de Los dos amantes del cielo, integrando-a na linha temática de Calderón, que a converte num dom divino, a que subjaz a contemplação e a renúncia; Margit Frenk analisa uma composição hispano-árabe, Diley vj namxi, integrada num cancioneiro manuscrito catalão da segunda metade do século $\mathrm{XV}$, indagando sinais de contacto entre a tradição lírica árabe e a hispânica; Maria Ana Ramos convoca a figura histórica de Afonso III, provável compilador ou conselheiro da compilação do Cancioneiro da Ajuda, encontrando, sobretudo, na componente musical do cancioneiro uma evidência da intervenção do rei; María del Valle Ojeda Calvo contrapõe os dois galãs de Callar en buena ocasión o Bueno es callar? de Antonio Mira de Amescua, para fortalecer o argumento de que Sancho, um dos galãs, encarna sumamente a virtude do silêncio fixada na tradição popular espanhola; María Jesús Fernández revê criticamente as apreciações que foram consagradas nos séculos XIX e XX ao teatro pós-vicentino e propõe novas aproximações, através da Literatura Comparada e dos Estudos Culturais, à idoneidade de um teatro tido por menor; Maria José Palla, a partir de uma leitura crítica da obra de Henrique da Mota,

nomeadamente do Processo de Vasco Abul, reflecte sobre o lugar ocupado pelo autor no cânone teatral de quinhentos; Mariana Masera destaca o simbolismo amoroso do hilo de oro e da fuente, referências da lírica medieval, que estabelecem entre si complexas relações que expõem a própria natureza do fenómeno poético;

Peter Dronke apresenta composições inéditas que acredita serem tributáveis a Hildegard de Bingen, associando-Ihes leituras que clarificam a semântica do sagrado; Rip Cohen traça a evolução das cantigas de amigo, cujas raizes remontam a uma matriz tradicional, ao longo do século XIII, a qual culmina em sequências teatralizadas na corte de Afonso X; Samuel G. Armistead compara as baladas tradicionais hispânicas com as dos Balcãs, inventariando relações entre elas, que podem ser alvo de investigação mais extensiva através do levantamento da tipologia textual envolvida; Stanislav Zimic esclarece as ironias e paradoxos que Cervantes utiliza no remate das suas comédias, fazendo-Ihes corresponder a justa compreensão da intencionalidade de que Cervantes as investiu; Teresa Araújo faz um levantamento de alusões ao Romanceiro velho nas cartas camonianas, reivindicando que estas funcionam como metáforas, às quais deve surgir associada a reavaliação do produto estético da recuperação literária da tradição; Thomas R. Hart revisita a obra de Stephen Reckert Beyond Chrysanthemums para actualizar o dominio de referência das cantigas de amigo, em que o eu poético feminino deriva da intencionalidade masculina; Vicenç Beltran examina a integração da poesia oral no cânone literário castelhano, concluindo que a mesma aportou à poesia espanhola a capacidade de designar a dimensão concreta das vivências pessoais e impressões perceptivas.

Já o texto moderno, incidindo ainda em temas caros a Stephen Reckert, é objecto de doze contribuições: António Manuel de Andrade Moniz pondera a pertinência da articulação da Semiologia com a Semiótica, enquanto instrumentos teóricos da Literatura, delimitando a linguagem das lágrimas como exemplo dessa articulação; Carlos Nogueira aborda a apropriação do popular, enquanto infra-estrutura, em Mãe pobre, de Carlos de Oliveira, autor que desvela uma nova dialéctica entre culto e popular; D. Gareth Walters identifica como motivo central em Passos da cruz, de Fernando Pessoa, a presença de um sujeito passivo, que rubrica uma apreensão misteriosa do mundo; Fernando Cabral Martins faz corresponder os esquemas de repetição prosódica, fonológica e rítmica do poema De tarde a uma intenção de Cesário Verde: a equivalência entre poema e imagem dotada de um significado; Graça Videira Lopes cumpre um programa de leitura do livro $A$ faca não corta o fogo, de Herberto Helder, resgatando citações, discursos e perguntas que comprovam a modernidade da obra; Ivan Teixeira examina a intertextualidade entre 0 alienista, de Machado de Assis, e The System of Dr. Tarr and Prof. Fether, de Edgar Allan Poe, a qual assenta no tópico do mundo às avessas, no uso da alegoria e na exploração do grotesco; Juan José Lanz procura levar a prática da intertextualidade para além dos limites formais habitualmente impostos, num cotejo paralelo da poesia de Luis Alberto de Cuenca e de Jon Juaristi; K. David Jackson propõe uma viagem ao Japão de Wenceslau de Morais, através da sua obra Ó-Yoné e Ko-Haru, elegendo como pares de conceitos fundamentais a musa e a cultura, a narração e a memória; Luisa Trias Folch demarca os elementos da tradição popular ibérica no entremez 0 homem da vaca e o poder da fortuna, de Ariano Suassuna, mostrando em que medida cunham a obra; Maria de Lourdes Pereira caracteriza a linguagem de Ana Hatherly como tenaz adestradora na arte de desvendar a realidade, intersecção de planos e teias subliminares, na recusa da atrofia da palavra e de quem nela se decifra; Nicolás Extremera Tapia avalia a identificação toureiro/ poeta na obra de João Cabral de Melo Neto, reportando-se em particular a Alguns toureiros, onde também se encontram vários outros temas alusivos à cultura espanhola; Pedro M. Piñero Ramírez dá-nos conta de como o cantar folclórico espanhol incorpora muitos elementos da tradição popular antiga, com destaque para certos estribilhos.

Este rol de partilha (Evocatio), inspiração (Inventio) e sapiência (Eruditio) é recheio de um livro com mais de 700 páginas, de revisão cuidada, e serve o propósito de deixar mais um justo testemunho do imenso contributo, em espírito e letra, de que Stephen Reckert nos faz depositários. 